\title{
Numerical Investigation of Oil Gas Separation with the Use of VOF CFD
}

\author{
Sorin Tomescu \\ Screw Compressors Department \\ NRDI for Gas Turbines COMOTI \\ Bucharest, Romania \\ sorin.tomescu@comoti.ro
}

\author{
Ioana Octavia Bucur \\ Computational Fluid Dynamics Department \\ NRDI for Gas Turbines COMOTI \\ Bucharest, Romania \\ ioana.bucur@comoti.ro
}

\begin{abstract}
In this research paper, a numerical study regarding gas-oil separation is presented. Employing the geometry of a classic separator used by the NRDI for Gas Turbines COMOTI and a Computer-Aided Design (CAD) software, the computational domain was defined. To perform the Computational Fluid Dynamics (CFD) investigation, the mesh was created with the ANSYS Meshing tool, and the ANSYS CFX was employed as a solver. The computational domain was split into 5 subdomains, 3 were fluid and 2 were defined as porous media. The volume porosity, loss model, and permeability were set up. In terms of turbulence flow, the standard $k-\varepsilon$ model was adopted. The results of the numerical calculations in terms of oil volume fraction and streamline profiles were used to analyze the separator configuration. The results show that the numerical investigation with the VOF (Volume of Fluid Method) - CFD model is capable of analyzing the performance of a two-phase separator equipped with two demisters-porous media.
\end{abstract}

Keywords-two-phase separator; computational fluid dynamics; volume of fluid; porous media; demister

\section{INTRODUCTION}

Technological evolution is currently mainly based on fossil fuels and their impact will continue to persist, although the trend is to redirect to the use of renewable energy with low environment impact and reduced pollution emissions [1]. In the petroleum extraction industry, air at high pressure is often employed in the oil extraction and recovery processes, which are complex procedures that require advanced installations [2]. Systems that can provide the needed amount of pressurized air for the extraction process, can be screw compressors with oil injection, which can raise the air pressure up to 40 bars [3]. In general, an oil-injected screw compressor developed for the petroleum and petrochemical industries is provided with a complex lubrication oil system that incorporates separator vessels. The separator vessels mainly consist of an inlet, a demister pad, and an outlet and they should ensure an efficient oil-gas separation. The process along with various configurations for the separator, are discussed broadly in [4]. Figure 1 illustrates a complex screw compressor with oil injection equipment, developed by the NRDI for Gas Turbines COMOTI. The use of such a system implies oil-air separation, which can be done using a separator vessel [5] that is provided with filters capable to retain the oil particle and separate them from the pressurized air [6]. A schematic presentation of a classic two-phase separator can be observed in Figure 2.

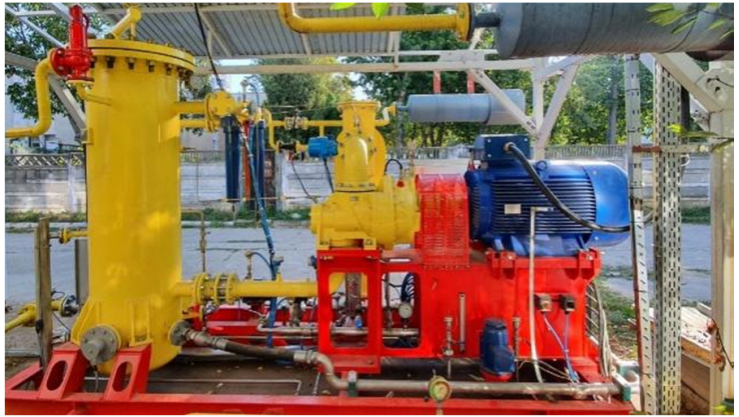

Fig. 1. Screw compressor installation.

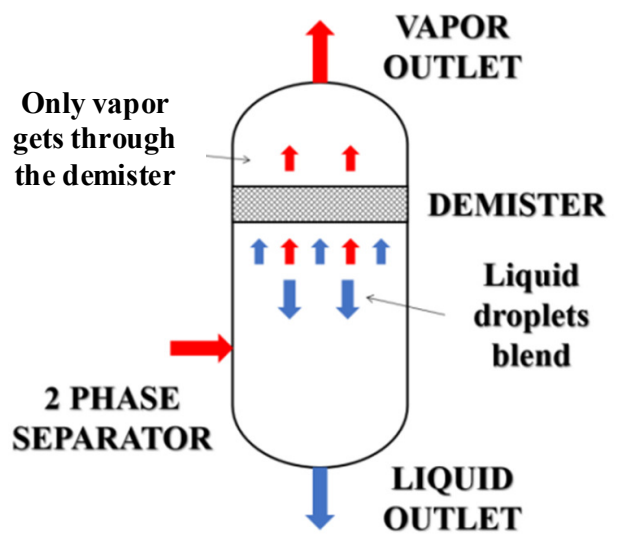

Fig. 2. Two-phase separator principle.

The efficiency evaluation of a two-phase separator can be done by employing the Volume of Fluid (VOF) method. This method is broadly applied in Computational Fluid Dynamics (CFD) for various flow applications such as the dam-break problem or the surge propagation in a dry channel, as well as the one identified above, i.e. the efficiency evaluation of a twophase separator. The method is best suited for the mentioned applications as it manages to track vapor-liquid interference while giving various alternatives for the reconstruction of the interface with precision whilst preserving the fractional volume 
of the fluid [7]. CFD tools have been proven to be reliable flow investigation instruments and have an important role in the design and optimization processes of complex systems, having large applications in the turbomachinery industry [8].

The use of CFD methods for the investigation of oil particles behavior in a separator vessel is studied in $[9,10]$. In [9], the conducted research confirms that CFD tools and methods are accurate by comparing the numerical results with the experimental data. On the other hand, the authors in [10] largely present various CFD studies of separators using the VOF method, concluding that the numerical approach has numerous benefits, being cost effective and flexible with regard to design alterations. Furthermore, using the numerical results, the optimization of oil-air separation process leads to enhanced separator vessel designs capable to capture up to 10 micrometer oil particles [11]. In [12], the authors use the Rosin Rammler distribution [13] to conduct a numerical investigation employing the ANSYS Fluent, for the oil droplet distribution at the inlet of a separator vessel using a multiphase model. In [14], the authors apply CFD tools for the investigation of the flow through a separator vessel with different inlet designs, concluding that CFD methods represent a valuable tool for the performance evaluation and optimization processes of separator vessels. Besides numerical alternatives, the flow in such systems can also be investigated using advanced measurement techniques as the Capacitance Wire Mesh Sensor (WMS) and the Electrical Capacitance Tomography (ECT) [15].

This paper aims to numerically investigate the oil/air separation process in a separator vessel by using ANSYS CFX, employing the VOF method.

\section{Methodology}

This section addresses the computational domain creation, mesh generation, and case set up for the numerical investigation of the oil/air separation process.

\section{A. Computational Domain Creation}

The computational domain was generated using the 3D CAD model of the separator vessel by utilizing the Boolean function. Figure 3 depicts the computational domain that is divided into 5 subdomains: 3 defined as fluid and 2 with porous media proprieties.

\section{B. Mesh Generation and Boundary Conditions}

The grid was generated based on a hybrid scheme by combining tetrahedral and hexahedral elements. Due to the complex geometry of the inlet and outlet domains, the mesh for these zones was automatically generated with ANSYS Meshing. The maximum element size was set at $50 \mathrm{~mm}$. For the demister domains, with porous media characteristics, the blocking method was employed in ICEM in order to generate the grid. Mesh statistics are detailed in the Figure 4 and the resulting mesh is illustrated in Figure 5. The quality of the grid is visualized in Figure 6, for both types of elements tetrahedral and hexahedral. It can be observed that only a negligible fraction of cells had poor quality.

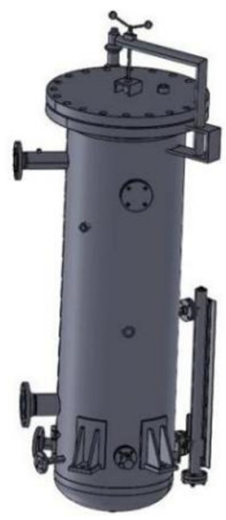

(a)

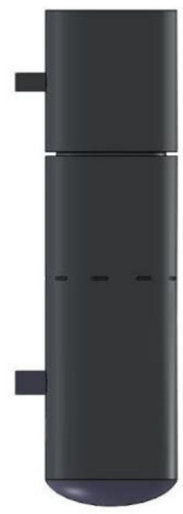

(b)

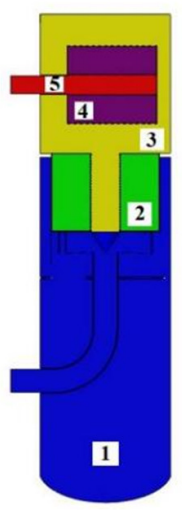

(c)
Fig. 3. Computational domain. (a) 3D CAD model for the separator vessel, (b) computational domain prepped for CFD, (c) computational domain cross plane: 1, 3, 5 fluid subdomains; 2, 4 porous media properties subdomains.

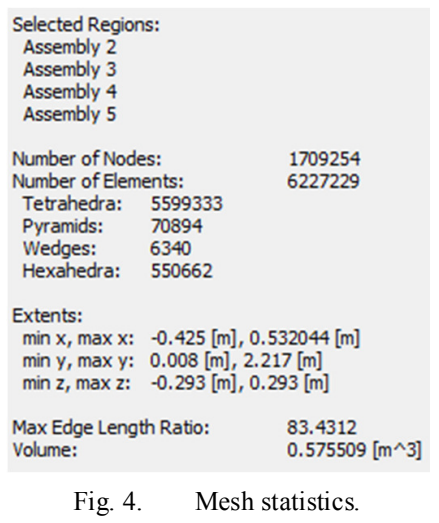

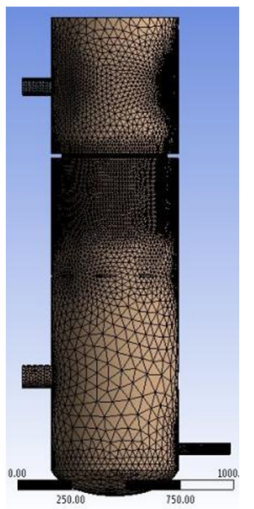

(a)

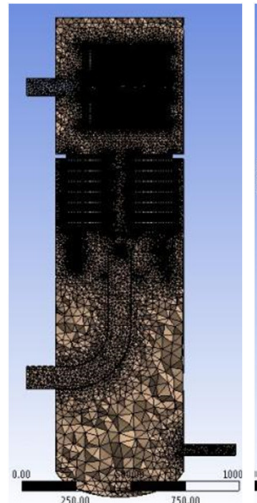

(b)

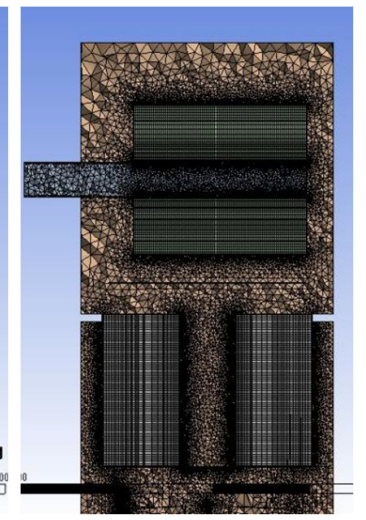

(c)
Fig. 5. Mesh for the numerical investigation. (a) Separator mesh, (b) cross plane view, (c) close-up on demister mesh.

The boundary conditions for the case set-up are described in Table I. A static pressure inlet boundary type and the volume fraction for each phase were defined for the fluid inlet. Regarding the porous media zones, the volume porosity was set at 0.7 with isotropic loss model and $3.8 \mathrm{e}-05 \mathrm{~m}^{2}$. Figure 7 illustrates the boundary conditions that were previously described. 


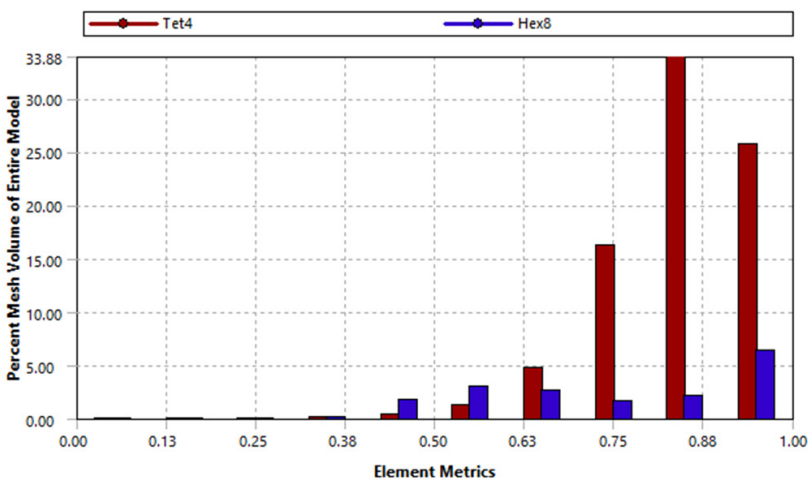

Fig. 6. Element quality.

TABLE I. BOUNDARY CONDITIONS

\begin{tabular}{|c|c|}
\hline Location & BC Description \\
\hline INLET & $\begin{array}{c}\text { Boundary type: static pressure } \\
\text { Relative pressure [bar]: } 22.5 \\
\left.\text { Static Temperature [ }{ }^{\circ} \mathrm{C}\right]: 80\end{array}$ \\
\hline OUTLET & $\begin{array}{c}\text { Boundary type: Bulk Mass Flow Rate } \\
\text { Mass flow rate [kg/s]: 0.2 }\end{array}$ \\
\hline OIL OUTLET & $\begin{array}{c}\text { Boundary type: Bulk Mass Flow Rate } \\
\text { Mass flow rate [kg/s]: } 2.25\end{array}$ \\
\hline WALLS & $\begin{array}{c}\text { Boundary type: Wall } \\
\text { No-slip condition }\end{array}$ \\
\hline
\end{tabular}

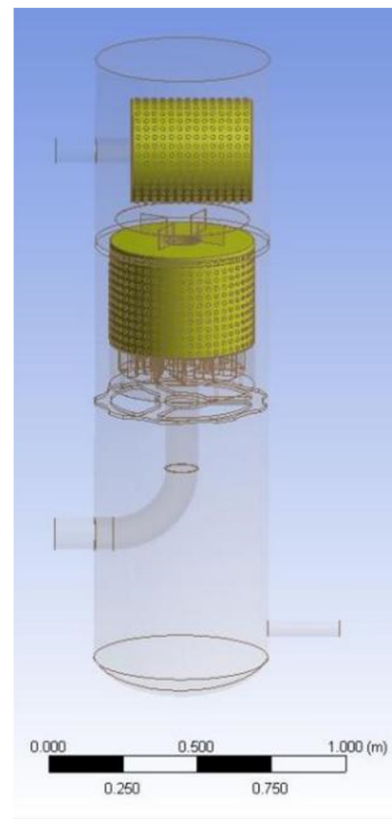

(a)

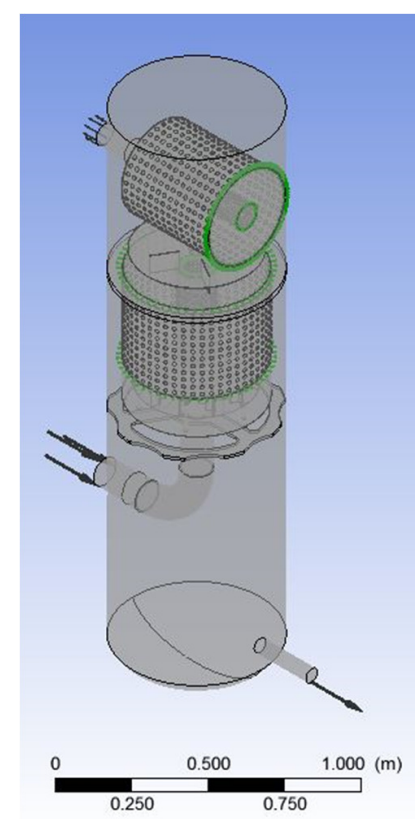

(b)
Fig. 7. (a) Computational domain, (b) boundary conditions.

The flow through the gas-oil separator equipped with two demisters was numerically modeled by solving the Unsteady Reynolds-Averaged Navier Stokes (URANS) equations with the standard $k-\varepsilon$ turbulence model. The transport equations for this turbulence model are presented below. is:

The transport equation for the turbulent kinetic energy $(k)$

$$
\begin{aligned}
& \frac{\partial k}{\partial t}+\bar{u} \frac{\partial k}{\partial x}+\bar{v} \frac{\partial k}{\partial y}+\bar{w} \frac{\partial k}{\partial z}= \\
& =\frac{1}{\rho}\left[\frac{\partial}{\partial x}\left(\left(\mu+\frac{\mu_{t}}{\sigma_{k}}\right) \frac{\partial k}{\partial x}\right)+\frac{\partial}{\partial y}\left(\left(\mu+\frac{\mu_{t}}{\sigma_{k}}\right) \frac{\partial k}{\partial y}\right)+\frac{\partial}{\partial z}\left(\left(\mu+\frac{\mu_{t}}{\sigma_{k}}\right) \frac{\partial k}{\partial z}\right)\right]+ \\
& +\frac{1}{\rho} \sum_{i, j} \tau \tau_{t i j} \frac{\partial \bar{u}_{i}}{\partial x_{j}}-\varepsilon
\end{aligned}
$$

where $\rho$ represents the density, $\mu$ the dynamic viscosity, $\mu_{t}$ the turbulent viscosity, and $\sigma_{k}$ the turbulent Prandtl number for kinetic energy.

The transport equation for the turbulent kinetic energy dissipation $(\varepsilon)$ is:

$$
\begin{aligned}
& \frac{\partial \varepsilon}{\partial t}+\bar{u} \frac{\partial \varepsilon}{\partial x}+\bar{v} \frac{\partial \varepsilon}{\partial y}+\bar{w} \frac{\partial \varepsilon}{\partial z}= \\
& =\frac{1}{\rho}\left[\frac{\partial}{\partial x}\left(\left(\mu+\frac{\mu_{t}}{\sigma_{\varepsilon}}\right) \frac{\partial \varepsilon}{\partial x}\right)+\frac{\partial}{\partial y}\left(\left(\mu+\frac{\mu_{t}}{\sigma_{\varepsilon}}\right) \frac{\partial \varepsilon}{\partial y}\right)+\frac{\partial}{\partial z}\left(\left(\mu+\frac{\mu_{t}}{\sigma_{\varepsilon}}\right) \frac{\partial \varepsilon}{\partial z}\right)\right]+ \\
& +C_{\varepsilon 1} \frac{\varepsilon}{\rho k} \sum_{i, j} \tau_{t i j} \frac{\partial \bar{u}_{i}}{\partial x_{j}}-C_{\varepsilon 2} \frac{\varepsilon^{2}}{k}
\end{aligned}
$$

where $\sigma_{\varepsilon}$ is the turbulent Prandtl number for dissipation and $C_{\varepsilon 1}$ and $C_{\varepsilon 2}$ are constants.

\section{Results}

The 3D CFD investigation was a transient one with a total flow time duration of $50 \mathrm{~s}$ and a time step size that was set at $0.01 \mathrm{~s}$. For this study, a multiphase homogeneous model with no heat transfer from the working fluid to the vessel walls was adopted. The evolution of the volumetric mass fraction of oil was investigated, as well as the development of the streamlines.

Figure 8 describes the oil volume fraction for different moments of time in the simulation. The regions where only oil is present are depicted with red, whereas the dark blue zones represent the areas without oil. It can be observed that the separation process is efficient. After the initialization stage (Figure 8(a), Time $=0 \mathrm{~s}$ ), where the oil level is defined according to the real operational conditions, the mixture of oil and gas is noticeable in the feeding pipe, but oil particles detectable above the region 2 (demister) are within reasonable boundaries at any moment of time. After region 4 (second demister), only a ratio of $0.1 \%$ of the inlet oil eludes the separation process and slips through the gas outlet.

In [16], the authors investigated numerically the performances of a two-phase separator and improved its internal configuration, reaching an efficiency of $99.49 \%$. The high efficiency of $99.9 \%$ of the system evaluated in this paper can save up to $33.2 \mathrm{~kg} / \mathrm{h}$ of oil in comparison with the enhanced geometry from the mentioned paper. Thus, the oil gas separation procedure is fulfilled properly and the methodology adopted for numerical evaluation is accurate. 


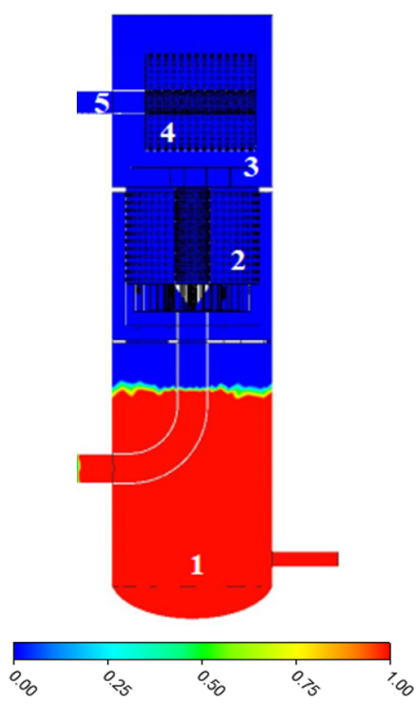

(a)

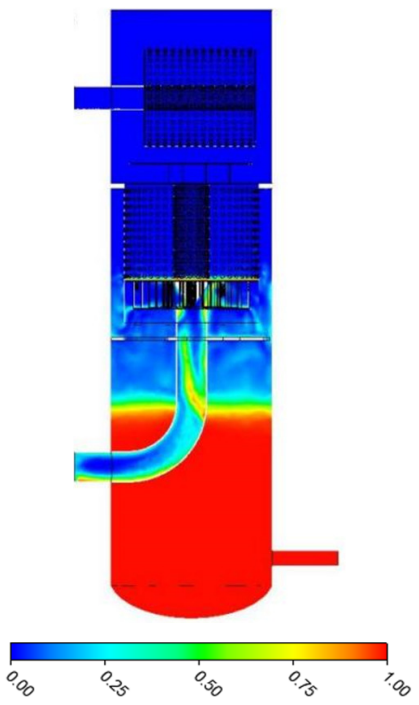

(c)

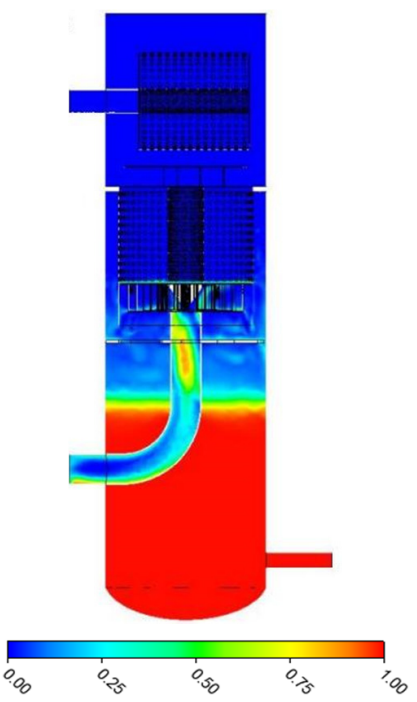

(b)

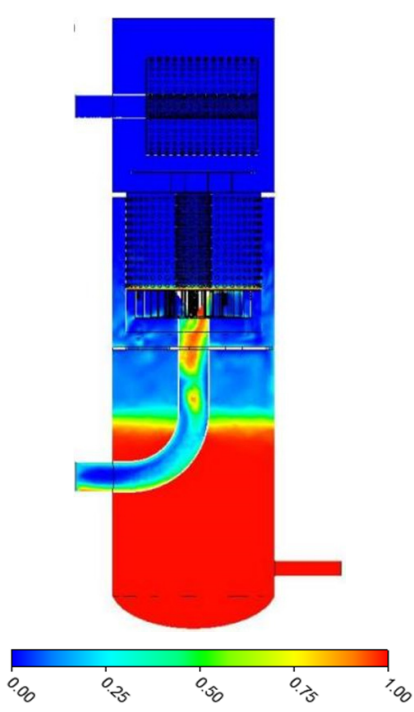

(d)

Fig. 8. Oil volume fraction for different moments in the simulation: (a) $0 \mathrm{~s}$, (b) $10 \mathrm{~s}$, (c) $20 \mathrm{~s}$, and (d) $30 \mathrm{~s}$.

The 2D streamlines are illustrated in Figure 9. Cross planes multiple recirculation zones can be identified, but this phenomenon does not have a negative influence on the overall performance of the separator as the vortexes are developed for low values of velocity. According to the presented streamlines, the velocity of the mixture slightly accelerates as it exits the feeding pipe and enters the separator. An increase in velocity is also noticeable at the liquid outlet, which is explained by the abrupt area reduction. Regarding the velocity of the gas, it is conspicuous from Figure 9 that its velocity increases slightly in time after the first demister (Figure 8(a), region 2) and more obvious after the second one (Figure $8(\mathrm{a})$, region 4 ) at the gas outlet duct (Figure 8(a), region 5).

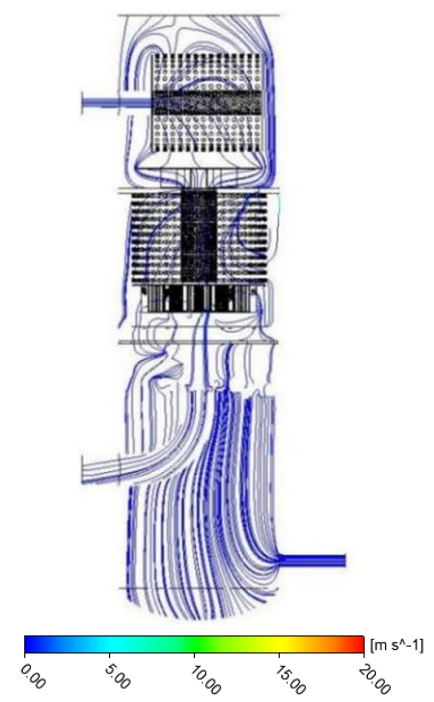

(a)

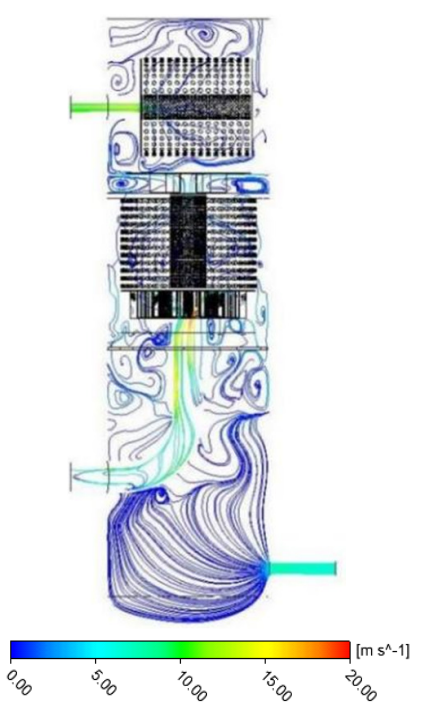

(c)

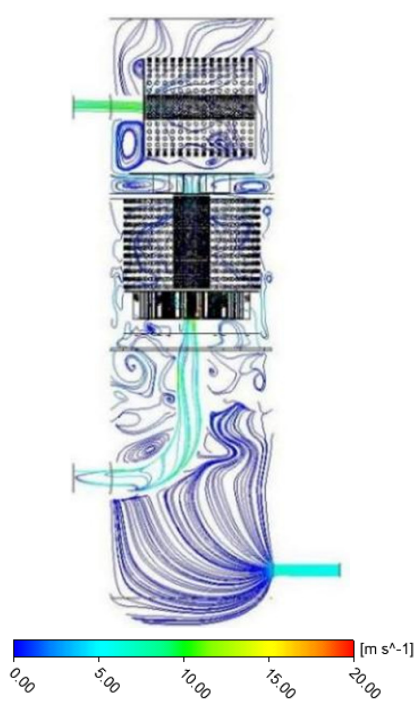

(b)

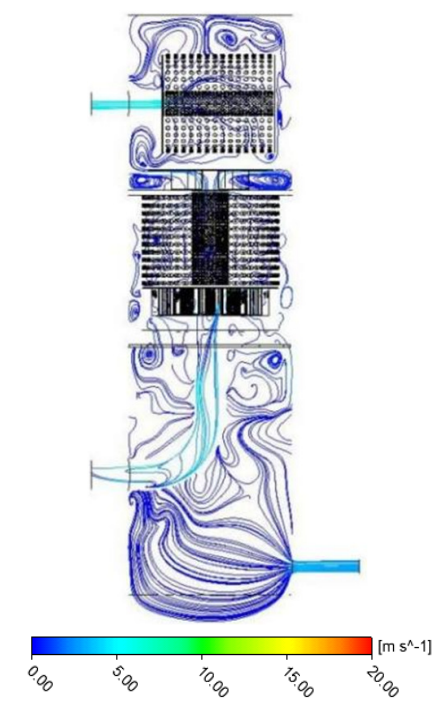

(d)
Fig. 9. Streamlines for different moments in the simulation. (a) $0 \mathrm{~s}$, (b) $10 \mathrm{~s}$, (c) $20 \mathrm{~s}$, and (d) $30 \mathrm{~s}$

The flow behavior of the investigated phenomenon and the obtained results are in agreement with the results from similar works in the field [17]. In [18], a similar CFD investigation is conducted but in terms of particle size it can only capture oil particles that are bigger than $100 \mu \mathrm{m}$, whereas the method adopted for the current CFD analysis is more precise, as it allows the visualization of oil particles bigger than $10 \mu \mathrm{m}$.

\section{CONCLUSIONS}

In this paper, the efficiency of a gas-oil separator was numerically investigated with the use of the ANSYS CFX software. A two-phase homogeneous model was defined for a computational domain with 5 subdomains, 3 defined as fluid and 2 as porous media, capable to capture the oil particles that are bigger than $10 \mu \mathrm{m}$. For the study of the oil flow in the separator vessel, a volume fraction evolution is presented 
throughout the simulation. After a flow time of 50 s only $0.1 \%$ of the inlet oil is escaping through the gas outlet. The present research contribution for the addressed field consists in a welldefined methodology for the numerical investigation of oil gas separation, with the addition of successfully employing the VOF method for this application. The paper's contents broadly describe the stages leading to the numerical evaluation, concentrating on mesh generation and characteristics, as well as on case set-up and turbulence model selection.

Future work will consist of a grid influence study and the results will be compared with the experimental data from testing campaigns. The testing facility is depicted in Figure 10.

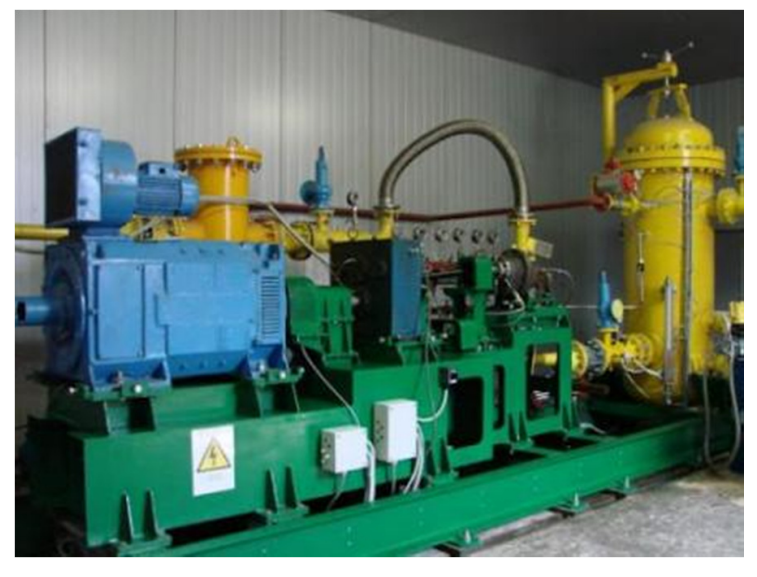

Fig. 10. Testing facility.

\section{ACKNOWLEDGMENT}

This research was supported by the "NUCLEU" Program TURBO 2020+, grant number 2N/2019, supported by the Romanian Ministry of Research, Innovation and Digitalization.

\section{REFERENCES}

[1] C. Zou, Q. Zhao, G. Zhang, and B. Xiong, "Energy revolution: From a fossil energy era to a new energy era," Natural Gas Industry B, vol. 3, no. 1, pp. 1-11, Jan. 2016, https://doi.org/10.1016/j.ngib.2016.02.001.

[2] T. Paulauskiene, "Petroleum Extraction Engineering," in Recent Insights in Petroleum Science and Engineering, M. Zoveidavianpoor, Ed. IntechOpen, 2018, https://doi.org/10.5772/intechopen.70360.

[3] M. Nitulescu, C. Slujitoru, and V. Petrescu, "Case Study regarding the test of the new screw compressor with high delivery pressure - 45 bara on the test bench (with air)," INCAS BULLETIN, vol. 4, no. 4, pp. 151159, Dec. 2012, https://doi.org/10.13111/2066-8201.2012.4.4.14.

[4] W. J. Milligan, D. I. Muir, and D. K. Harrison, "Oil level measurement in oil-injected screw compressor packages used in the petroleum, petrochemical, refrigeration and fuel gas markets," in 8th International Conference on Compressors and their Systems, London, UK, Jan. 2013, pp. 77-85, https://doi.org/10.1533/9781782421702.2.77.

[5] S. F. A. Bukhari, I. Ismail, and W. Q. Yang, "Visualising oil separator vessel and decision-making for control," in 4th World Congress in Industrial Process Tomography, 2005, pp. 855-860.

[6] S. Kaiser, A. Gugelfuß, A. Gyurkovich, M. Rupp, C. Mehring, and M. Piesche, "Characterization of oil injected screw compressors and air/oil separators at realistic operating pressures," Aerosol Science and Technology, vol. 53, no. 11, pp. 1311-1321, Nov. 2019, https://doi.org/ 10.1080/02786826.2019.1659937.

[7] N. D. Katopodes, Free-Surface Flow: Computational Methods, Oxford, UK: Butterworth-Heinemann, 2019.
[8] V. Dragan, I. Malael, and B. Gherman, "A Comparative Analysis Between Optimized and Baseline High Pressure Compressor Stages Using Tridimensional Computational Fluid Dynamics," Engineering, Technology \& Applied Science Research, vol. 6, no. 4, pp. 1103-1108, Aug. 2016, https://doi.org/10.48084/etasr.696.

[9] S. C. K. De Schepper, G. J. Heynderickx, and G. B. Marin, "CFD modeling of all gas-liquid and vapor-liquid flow regimes predicted by the Baker chart," Chemical Engineering Journal, vol. 138, no. 1, pp. 349-357, May 2008, https://doi.org/10.1016/j.cej.2007.06.007.

[10] A. P. Laleh, W. Y. Svrcek, and W. D. Monnery, "Design and CFD studies of multiphase separators - a review," The Canadian Journal of Chemical Engineering, vol. 90, no. 6, pp. 1547-1561, 2012, https://doi.org/10.1002/cjce.20665.

[11] G. Cheng, L. Y. Yan, and H. Zhou, "The Oil Vessel Structure Optimization by the use of CFD in the Oil Injection Twin-Screw Compressor," presented at the International Compressor Engineering Conference, West Lafayette, IN, USA, 2004, Art. no. 1714.

[12] N. Kharoua, L. Khezzar, and H. Saadawi, "CFD Simulation of ThreePhase Separator: Effects of Size Distribution," presented at the ASME 2013 Fluids Engineering Division Summer Meeting, Incline Village, NV, USA, Jul. 2013, Art. no. FEDSM2013-16322, https://doi.org/ 10.1115/FEDSM2013-16322.

[13] P. A. Vesilind, "The Rosin-Rammler particle size distribution," Resource Recovery and Conservation, vol. 5, no. 3, pp. 275-277, Sep. 1980, https://doi.org/10.1016/0304-3967(80)90007-4.

[14] F. P. Lucas and R. Huebner, "Numerical Simulation of Single-Phase and Two-Phase Flows in Separator Vessels with Inclined Half-Pipe Inlet Device Applied in Reciprocating Compressors," Engineering, Technology \& Applied Science Research, vol. 8, no. 3, pp. 2897-2900, Jun. 2018, https://doi.org/10.48084/etasr.1993.

[15] L. A. Abdulkareem, "Identification of Oil-Gas Two Phase Flow in a Vertical Pipe using Advanced Measurement Techniques," Engineering, Technology \& Applied Science Research, vol. 10, no. 5, pp. 6165-6171, Oct. 2020, https://doi.org/10.48084/etasr.3679.

[16] A. Efendioglu, J. Mendez, and H. Turkoglu, "The numerical analysis of the flow and separation efficiency of a two-phase horizontal oil-gas separator with an inlet diverter and perforated plates," presented at the AFM2014, La Coruña, Spain, Jul. 2014, pp. 133-142, https://doi.org/ 10.2495/AFM140121.

[17] L. Z. Wang, X. Gao, J. M. Feng, and X. Y. Peng, "Research on the twophase flow and separation mechanism in the oil-gas cyclone separator," in 9th International Conference on Compressors and their Systems, London, UK, Sep. 2015, Art. no. 012075, https://doi.org/10.1088/1757899X/90/1/012075.

[18] V. Vijayan, M. Vivekanandan, R. Venkatesh, K. Rajaguru, and A. Godwin Antony, "CFD modeling and analysis of a two-phase vapor separator," Journal of Thermal Analysis and Calorimetry, vol. 145, no. 5, pp. 2719-2726, Sep. 2021, https://doi.org/10.1007/s10973-02009825-2. 